\title{
Potencial fitotóxico de Dicranopteris flexuosa (Schrad.) Underw. (Gleicheniaceae)
}

Valerí Schmidt da Silva ${ }^{1}$, Ana Carina da Silva Cândido ${ }^{1}$, Caroline Muller ${ }^{2}$, Valdemir Antônio Laura ${ }^{3}$, Odival Faccenda ${ }^{4}$, Euclésio Simionatto ${ }^{5}$, Sonia Corina Hess ${ }^{5}$ e Marize Terezinha Lopes Pereira Peres ${ }^{5,6}$

Recebido em 4/01/2010. Aceito em 10/12/2010

\begin{abstract}
RESUMO
(Potencial fitotóxico de Dicranopteris flexuosa (Schrad.) Underw. (Gleicheniaceae)). O objetivo deste trabalho foi determinar o potencial fitotóxico do extrato etanólico bruto e das frações semipurificadas de Dicranopteris flexuosa por meio de bioensaios de germinação e crescimento de Lactuca sativa L. (alface), Lycopersicon esculentum L. (tomate), Allium cepa L. (cebola) e Triticum aestivum L. (trigo) em laboratório e casa de vegetação e quantificar o teor total de fenóis e flavonóides dos extratos e frações. Nos bioensaios realizados em laboratório foram utilizadas quatro concentrações $\left(0,250,500,1000 \mathrm{mg} \mathrm{L}^{-1}\right)$, com quatro repetições de 50 sementes. A análise dos resultados indica redução da velocidade e/ou inibição da germinação, estímulo do crescimento da raiz das eudicotiledôneas e inibição da raiz adventícia das monocotiledôneas estudadas. Nos bioensaios realizados em casa de vegetação foram utilizadas as mesmas concentrações dos bioensaios em laboratório, com oito repetições de cinco sementes por vaso. A análise dos resultados indica que o comprimento da raiz foi afetado pelo extrato etanólico bruto, ocorrendo estímulo em tomate e inibição em cebola e trigo. A produção de massa seca da parte aérea foi estimulada na menor concentração em alface e trigo. A fração acetato de etila foi a que apresentou os maiores teores de fenóis e flavonóides totais. Embora os resultados sejam preliminares, observa-se que o extrato etanólico e as frações semipurificadas de D. flexuosa também contêm substâncias que interferem no crescimento das plântulas de alface, tomate, cebola e trigo.
\end{abstract}

Palavras-chave: crescimento, germinação, pteridophyta

\begin{abstract}
(Phytotoxic potential of Dicranopteris flexuosa (Schrad.) Underw. (Gleicheniaceae)). This work aimed to determine the phytotoxic potential of crude ethanol extract and semipurified fractions of Dicranopteris flexuosa on the germination and growth of Lactuca sativa L. (lettuce), Lycopersicon esculentum L. (tomato), Allium cepa L. (onion) and Triticum aestivum L. (wheat) in laboratory and greenhouse bioassays and determine total phenolic and flavonoid content. For the tests carried out in laboratory, four concentrations $(0,250,500,1000$ mg.L.- $)$ were applied to four replicates of 50 seeds each. Analysis of the results indicates a reduction in speed and/or inhibition of germination, stimulation of root growth in eudicots and root inhibition in the monocots studied. For the bioassays carried out in the greenhouse, the plant materials were applied at the same concentrations as those in the laboratory bioassays, with eight replicates of five seeds each. Analysis of the results indicates that root length was affected by the crude ethanol extract resulting in stimulation in tomato and inhibition in onion and wheat. Aerial dry mass was higher at the lower concentration in lettuce and wheat. The ethyl acetate fraction presented higher content of total phenols and flavonoids. Although the results are preliminary, they indicate that ethanol extract and semipurified fractions of $D$. flexuosa contain substances that modify seedling growth of lettuce, tomato, onion and wheat.
\end{abstract}

Key words: growth, germination, pteridophyta

\footnotetext{
1 Universidade Federal de Mato Grosso do Sul, Programa de Pós-Graduação em Biologia Vegetal, Campo Grande, MS, Brasil

2 Universidade Federal de Mato Grosso do Sul, Departamento de Ciências Biológicas, Campo Grande, MS, Brasil

3 Embrapa Gado de Corte, Campo Grande, MS, Brasil

4 Universidade Estadual de Mato Grosso do Sul, Departamento de Computação, Dourados, MS, Brasil

5 Universidade Federal de Mato Grosso do Sul, Departamento de Hidráulica e Transporte, Campo Grande, MS, Brasil

6 Autor para correspondência: marizeperes@hotmail.com
} 


\section{Introdução}

Em muitos ecossistemas as plantas tendem a se estabelecer em conjuntos puros, o que é atribuído à liberação de toxinas (aleloquímicos), dificultando ou impedindo o estabelecimento de outras espécies em sua proximidade. $\mathrm{O}$ potencial alelopático demonstrado por essas espécies pode auxiliar na busca por herbicidas ambientalmente menos tóxicos e mais específicos (Macías et al. 1998).

Historicamente, investigações alelopáticas são iniciadas a partir de observações de campo, as quais sugerem uma modificação no padrão de vegetação (Einhellig 2002). Um mecanismo de dominância pode ser visualizado em algumas pteridófitas que crescem formando associações quase puras onde poucas espécies coexistem (Gleissman \& Muller 1972). Nestes locais, espécies associadas parecem ser severamente inibidas e, muitas vezes, excluídas dos aglomerados. A aparente exclusão de outras espécies dessas áreas pode estar relacionada à liberação de compostos do metabolismo secundário dessas plantas para o solo. Como exemplos de samambaias que possuem esse mecanismo destacam-se Pteridium aquilinum (L.) Kuhn (Gliessman \& Muller 1978) e as Gleicheniaceae: Gleichenia pectinata (Willd.) (Peres et al. 1998), Dicranopteris linearis (Burm. f.) Underw (TetVun \& Ismail 2006) e Dicranopteris flexuosa (Schrad.) Underw (Soares \& Vieira 2000).

Estudos químicos com os gêneros Stromatopteris, Schizeae, Gleichenia, Hymenophyllum e Cardiomanes (Gleicheniaceae) levaram ao isolamento dos flavonóides quercetina e kaempferol (Wallace \& Markham 1978) além de diterpenóides (6S, 13S)-clerodano-3,14diene-6,13-diol e diterpenóides glicosilados como $(6 \mathrm{~S}, 13 \mathrm{~S})-6-\mathrm{O}-[\beta-\mathrm{D}-\mathrm{Glu}-(1 \rightarrow 4)-\alpha-\mathrm{L}-\mathrm{Rha}]-13-\mathrm{O}-[\alpha-\mathrm{L}-$ Rha- $(1 \rightarrow 4)-\beta$-D-Fuc]-clerodano 3,14-diene; (6S,13S)6-O-[ $\beta$-Glu]-13-O-[ $\beta$-Fuc- $(1 \rightarrow 2)$ - $\alpha$-Rha]-clerodano3,14-diene (Aoki et al. 1997); 13-O-rhamnopiranosil(+)-3ß-hidroximanool (Munesada et al. 1992). Aoki et al. (1997) e Munesada et al. (1992) verificaram que os terpenóides isolados de Gleichenia japonica Spreng. possuem potencial alelopático sobre alface, modificando sua capacidade germinativa.

Dicranopteris flexuosa (Schrad.) Underw. (Gleicheniaceae) apresenta ampla distribuição por toda a América Tropical, devendo provavelmente ocorrer em todo o território brasileiro, crescendo de modo geral em locais abertos com solo úmido e pobre e, predominantemente, ocorrendo em densas formações (Windish 1994). Estudos preliminares dos extratos aquosos desta espécie indicaram seu elevado potencial alelopático (Soares \& Vieira 2000).

Neste trabalho teve-se como objetivo avaliar o potencial de atividade fitotóxica de $D$. flexuosa por meio de bioensaios em laboratório e casa de vegetação; bem como quantificar o teor total de fenóis e flavonóides do extrato e frações.

\section{Material e métodos}

Dicranopteris flexuosa foi coletada num fragmento de cerrado perto de um córrego na Fazenda Curupi, município de Ponta Porã, Estado de Mato Grosso do Sul (MS), Brasil, nas coordenadas geográficas $22^{\circ} 01^{\prime} 30,2^{\prime \prime}-22^{\circ} 01^{\prime} 41,1^{\prime \prime} S$ e $55^{\circ} 39^{\prime} 11,8^{\prime \prime}-55^{\circ} 39^{\prime} 26,2^{\prime \prime} \mathrm{W}$, a $62 \mathrm{~m}$ de altitude, na rodovia estadual que liga o distrito de Itahum ao município Cabeceira do Apa, em 2001. Esse fragmento protege as nascentes do córrego São José, que deságua no rio Dourados. Foram coletadas frondes verdes para compor a exsicata e para confecção dos extratos. Após a coleta, as frondes verdes foram acondicionadas em saco plástico em freezer $\left(-7^{\circ} \mathrm{C}\right)$, até sua utilização. A espécie foi determinada pela Bióloga Leila Paes Clemente, Universidade Federal da Grande Dourados (UFGD), depositada sob número 615 no Herbário da UFGD, Dourados (MS), Brasil.

As frondes verdes de $D$. flexuosa foram reduzidas a pequenos fragmentos e submetidas à extração por meio de maceração com etanol (m/v, 1:2), a temperatura ambiente. Após sete dias, foi feita a filtragem em papel filtro e os materiais sólidos descartados, sendo posteriormente o solvente evaporado sob vácuo em evaporador rotativo, obtendo-se o EEB de D. flexuosa. Para a obtenção das FS, o EEB foi fracionado por partição líquido-líquido com hexano e acetato de etila, em funil de decantação, obtendo-se as frações: hexânica (FH), acetato de etila (FAE) e etanol-água (FEA) $(1: 10 \mathrm{v} / \mathrm{v})$. O teor de água do EEB e das FS foi determinado a partir de alíquotas $( \pm 0,1 \mathrm{mg})$ dos mesmos, submetidas à secagem $\left( \pm 100^{\circ} \mathrm{C}\right)$ em estufa por 10 horas, até que a massa fosse constante por dois dias consecutivos.

Para o preparo das soluções, o EEB e as FS (FH, FAE, FEA) foram pesados, levando-se em consideração o teor de água e dissolvidas em DMSO (Dimetilsulfóxido) a 0,1\% (Dayan et al. 2000), obtendo-se a solução estoque de 1000 $\mathrm{mg} \mathrm{L}^{-1}$; as concentrações de 500 e $250 \mathrm{mg} \mathrm{L}^{-1}$ foram obtidas por diluição. As soluções-teste foram tamponadas com solução de MES (Ácido 2-morfolinoetanosulfônico) a 10 $\mathrm{mM}$, e o pH foi ajustado para 6,0 com solução de $\mathrm{KOH}$ 0,1 $\mathrm{N}$ (Macias et al. 2000).

As soluções foram ensaiadas com as eudicotiledôneas: alface (Lactuca sativa L. cv. Grand rapids) e tomate (Lycopersicon esculentum Mill cv. Santa Clara), e com as monocotiledôneas: cebola (Allium cepa L. cv. Baia Periforme) e trigo (Triticum aestivum L. cv. RRS 220).

Para os bioensaios, aplicou-se a metodologia de Macias et al. (2000). As placas de Petri (9,0 cm de diâmetro) contendo papel filtro Whatman $n^{\circ} 1,0$, previamente autoclavadas, receberam 5,0 $\mathrm{mL}$ das soluções, preparadas nas concentrações de 250, 500 e $1000 \mathrm{mg} \mathrm{L}^{-1}$. Como controle utilizou uma solução de DMSO 0,1\%, a qual foi tamponada com MES a $10 \mathrm{mM}$, e o pH ajustado para 6,0 com solução de $\mathrm{KOH} 0,1 \mathrm{~N}$. Em seguida, distribuiu-se 50 diásporos das espécies-alvo (alface, tomate, cebola e trigo), aleatoriamente sobre cada disco de papel filtro. O delineamento experimental utilizado 
foi o inteiramente casualizado, envolvendo quatro ensaios simples (EEB, FH, FAE, FEA) com quatro tratamentos $(0$, 250, 500 e $1000 \mathrm{mg} \mathrm{L}^{-1}$ ), em quatro repetições.

As placas de Petri contendo os diásporos foram levadas a uma câmara de germinação tipo BOD, com condições de luz ( $160 \mathrm{~W}$, contínua para alface, fotoperíodo de $12 \mathrm{~h}$ para tomate e cebola e escuro para trigo), umidade ( $\pm 80 \%)$ e temperatura constante $\left(25^{\circ} \mathrm{C}\right.$ para alface e tomate, $15^{\circ} \mathrm{C}$ para cebola e trigo), adequadas a espécie alvo, conforme Brasil (1992).

A avaliação da germinação foi diária (sendo para alface a cada 12 horas), tendo como critério a protrusão radicular com no mínimo 2,0 mm de comprimento. Três dias após a protrusão radicular, foi feita a medida do comprimento da raiz e do hipocótilo/coleóptilo (dez plântulas por placa) utilizando-se papel milimetrado. Posteriormente essas plântulas foram levadas para secar em estufa a $60^{\circ} \mathrm{C}$ até peso constante, para a obtenção da matéria seca.

Os bioensaios em casa de vegetação foram semelhantes aqueles descritos por Barbosa et al. (2002). Para os bioensaios o EEB foi dissolvidos em solução nutritiva completa (Hoagland \& Arnon 1950) obtendo-se assim a soluçãoestoque na concentração de $1000 \mathrm{mg} \mathrm{L}^{-1}$. As concentrações de 500 e $250 \mathrm{mg} \mathrm{L}^{-1}$ foram preparadas por diluição. As soluções foram tamponadas com solução de MES (Ácido 2-morfolinoetanosulfônico) a $10 \mathrm{mM}$, e o pH foi ajustado para 6,0 (Macias et al. 2000), com solução de $\mathrm{KOH} \mathrm{0,1} \mathrm{N}$. Como controle, foi preparada uma solução com a mesma composição, mas sem o EEB. Nesses bioensaios foram utilizadas as mesmas espécies alvo dos bioensaios em laboratório: alface, tomate, cebola e trigo.

Antes da semeadura, cada vaso plástico $(7,0 \times 6,0 \mathrm{~cm}$, diâmetro e altura), recebeu $160 \mathrm{~g}$ de areia lavada, seca em estufa a $120^{\circ} \mathrm{C}$ e peneirada em peneira número 4 (diam. $192 \mathrm{~mm}$ x $358 \mathrm{~mm}$ x $85 \mathrm{~mm}$ ). No dia da semeadura, cada vaso foi saturado com a solução contendo os respectivos tratamentos, até atingir $80 \%$ da capacidade de campo; cinco diásporos de cada planta-alvo foram colocados em cada vaso numa profundidade de mais ou menos um centímetro. Os vasos foram mantidos em casa de vegetação a $\pm 25^{\circ} \mathrm{C} \mathrm{e}$ foram irrigados diariamente com água destilada, baseandose na perda de umidade dos vasos (Prates et al. 2000), e uma vez por semana com solução nutritiva completa (Hoagland \& Arnon 1950), ao invés de água destilada. Todos os tratamentos foram replicados oito vezes. $\mathrm{O}$ delineamento experimental usado foi de blocos casualizados.

Diariamente, foi anotado o número de plântulas emersas em cada vaso, para cálculo do índice de velocidade de emergência (IVE) e a porcentagem de plântulas emersas. Decorrido 28 dias após a semeadura, as plantas foram colhidas e, posteriormente, avaliou-se o comprimento da parte aérea e da raiz, sendo essas levadas para secagem em estufa a $60^{\circ} \mathrm{C}$ até peso constante para a obtenção da matéria seca, em gramas.

A porcentagem de plântulas germinadas/emersas foi calculada segundo metodologia descrita por Labouriau
(1983) e o índice de velocidade de germinação/emergência (IVG/IVE) segundo Maguire (1962) citado por Ferreira (2004).

Os dados foram submetidos à análise de variância (teste F) com nível de significância $\alpha=5 \%$ para os testes que envolveram comparação de mais de duas médias e teste de Dunnet para a comparação múltipla de duas médias, ou seja, para verificar quais concentrações do EEB e FS aplicados apresentaram diferenças significativas $(\mathrm{p}<0,05)$ em relação ao controle. Os resultados dos testes biométricos são apresentados como porcentagens em relação ao controle. Então, zero representa o controle, valores positivos representam estímulo e negativos representam inibição.

Foram realizados testes preliminares de cromatografia em camada delgada (CCD) em placas cromatográficas AL TLC silicagel 60 (Merk), a fim de detectar a presença de terpenóides, compostos fenólicos e alcalóides no EEB e nas FS. A revelação foi feita com reagentes indicadores, tais como solução de vanilina/etanol- $\mathrm{H}_{2} \mathrm{SO}_{4} 1,0 \%$ para terpenos, cloreto férrico 1,0\% para compostos fenólicos e reagente de Dragendorff para alcalóides (Lin \& Tang 2007).

O teor de fenóis totais foi determinado por meio de espectroscopia na região do visível utilizando o método Folin-Ciocalteu (Lin \& Tang 2007). Os extratos e frações foram dissolvidos em 5,0 $\mathrm{mL}$ de água destilada. Posteriormente, alíquotas de $1,0 \mathrm{~mL}$ dessa solução foram transferidas para balões de $50 \mathrm{~mL}$, sendo acrescentados $30 \mathrm{~mL}$ de água destilada, 2,0 $\mathrm{mL}$ do reagente Folin Ciocalteau e após seis minutos $6,0 \mathrm{~mL}$ de uma solução de carbonato de sódio $\left(\mathrm{Na}_{2} \mathrm{CO}_{3}\right) 20 \%$. Completou-se o volume do balão com água destilada (Lin \& Tang 2007). O controle foi preparado da mesma forma, contendo todos os reagentes exceto as amostras do EEB e FS. As soluções foram deixadas em repouso à temperatura ambiente e, precisamente após 1 hora e 30 minutos, fez-se a leitura no espectrofotômetro a $760 \mathrm{~nm}$. O teor de fenóis totais foi determinado por interpolação da absorbância das amostras contra uma curva de calibração construída com padrões de ácido gálico (25 a $600 \mu \mathrm{g} / \mathrm{mL}$ ) e expressos como $\mathrm{mg}$ de equivalentes de ácido gálico (EAG) por mg de extrato. Todas as análises foram realizadas em triplicata.

Para a quantificação do teor de flavonóides, primeiramente, uma curva com quercetina, tomada como substância de referência, foi construída utilizando-se concentrações de 5,0 a 300,0 $\mu \mathrm{g}$. O EEB e as FS $(8,0 \mathrm{mg})$ foram dissolvidas em $4,0 \mathrm{~mL}$ de etanol e posteriormente, alíquotas de 2,0 $\mathrm{mL}$ dessa solução foram transferidos para balões de $25 \mathrm{~mL}$, sendo acrescentado $1,0 \mathrm{~mL}$ de cloreto de alumínio (2,5\%), 1,0 $\mathrm{mL}$ de acetato de sódio (10\%) e completando-se o volume do balão com etanol. Como controle foi preparada uma solução, contendo todos os reagentes, exceto as amostras do EEB e FS. Decorridos 40 minutos foi feita a leitura de cada solução no espectrofotômetro a 425 nm (Lin \& Tang 2007). Todas as análises foram realizadas em triplicata. 


\section{Resultados e discussão}

Na germinação das eudicotiledôneas estudadas (Tab. 1), verificou-se que o extrato etanólico bruto (EEB), a fração hexânica (FH) e a fração etanol-água (FAE) reduziram o índice de velocidade de germinação (IVG) de alface e tomate $(\mathrm{p}<0,05)$, sendo as maiores reduções verificadas na maior concentração ensaiada da FH de 63,2\% e 23,7\% em alface e tomate, respectivamente, tendo como base de comparação o controle. Porém, apesar de atrasarem a germinação, apenas na concentração de $1000 \mathrm{mg} \mathrm{L}^{-1} \mathrm{da} \mathrm{FH}$, em alface, reduziu a percentagem de germinação, em relação ao controle.

O processo global da germinação é constituído por três processos parciais: embebição, ativação e crescimento intra-seminal. A dificuldade em estabelecer onde o processo começa e termina faz com que a determinação da germinação seja avaliada por um critério macroscópico: a protrusão da raiz primária (Ranal \& Santana 2006). Esse processo é menos sensível aos aleloquímicos do que o crescimento da plântula, mas a quantificação experimental é muito mais simples, pois para cada semente o fenômeno é discreto, germina ou não germina (Ferreira \& Áquila 2000). Como a germinabilidade é menos sensível aos aleloquímicos, muitas vezes o efeito é sobre outro parâmetro do processo (Ferreira 2004), como por exemplo, a velocidade de germinação.

Segundo Maguire (1962), citado por Ranal \& Santana (2006), o IVG é usado para avaliar o vigor das sementes, pois a redução no vigor da semente causa perda progressiva na capacidade produtiva, com a redução na uniformidade da germinação. A "Association of Official Seed Analysts" (AOSA) define vigor de sementes como "a propriedade da semente que determina o potencial para uma emergência rápida e uniforme e para o desenvolvimento de plântulas normais, sob uma ampla faixa de condições de campo" (Piña-Rodriguez et al. 2004). O vigor é reconhecido como um parâmetro para a caracterização do potencial fisiológico das sementes, indicando a maior ou menor probabilidade de sucesso após a semeadura (Marcos-Filho 2005). Os testes mais simples para a determinação de vigor das sementes são os de velocidade de desenvolvimento, cujos resultados podem ser obtidos pela análise do processo de germinação, mais especificamente, pelo IVG.

A análise dos resultados para eudicotiledôneas permite concluir que o EEB, FH e FAE afetaram o IVG (atrasando a germinação), entretanto, não causaram efeito na germinabilidade das espécies alvo ensaiadas, exceto a $\mathrm{FH}$ na

Tabela 1. Índice de velocidade de germinação (IVG) e germinabilidade (\%G) de alface e tomate submetidas a diferentes concentrações do extrato e frações de Dicranopteris flexuosa, em laboratório.

\begin{tabular}{|c|c|c|c|c|}
\hline \multirow[t]{2}{*}{ Alface } & \multicolumn{4}{|c|}{ IVG } \\
\hline & controle & $250 \mathrm{mg} \cdot \mathrm{L}^{-1}$ & $500 \mathrm{mg} \cdot \mathrm{L}^{-1}$ & $1000 \mathrm{mg} . \mathrm{L}^{-1}$ \\
\hline Extrato etanólico bruto & 33,70 & $32,30^{\mathrm{ns}}$ & $25,30^{*}$ & $26,30^{*}$ \\
\hline Fração hexano & 33,70 & $31,60^{\mathrm{ns}}$ & $20,10^{*}$ & $12,40^{*}$ \\
\hline Fração acetato de etila & 33,70 & $35,40^{\text {ns }}$ & $25,30^{*}$ & $28,00^{*}$ \\
\hline \multirow[t]{2}{*}{ Fração etanol água } & 33,70 & $36,10^{\mathrm{ns}}$ & $34,90^{\mathrm{ns}}$ & $35,50^{\mathrm{ns}}$ \\
\hline & \multicolumn{4}{|c|}{$\mathrm{G} \%$} \\
\hline Extrato etanólico bruto & 99,50 & $99,50^{\text {ns }}$ & $99,00^{\text {ns }}$ & $98,50^{\text {ns }}$ \\
\hline Fração hexano & 99,50 & $98,50^{\mathrm{ns}}$ & $94,50^{\mathrm{ns}}$ & $84,00^{*}$ \\
\hline Fração acetato de etila & 99,50 & $98,50^{\mathrm{n}}$ & $89,00^{\text {ns }}$ & $97,50^{\text {ns }}$ \\
\hline Fração etanol água & 99,50 & $98,50^{\mathrm{ns}}$ & $99,00^{\mathrm{ns}}$ & $97,50^{\mathrm{ns}}$ \\
\hline \multirow[t]{2}{*}{ Tomate } & \multicolumn{4}{|c|}{ IVG } \\
\hline & Controle & $250 \mathrm{mg} \cdot \mathrm{L}^{-1}$ & $500 \mathrm{mg} \cdot \mathrm{L}^{-1}$ & $1000 \mathrm{mg} \cdot \mathrm{L}^{-1}$ \\
\hline Extrato etanólico bruto & 15,20 & $13,50^{*}$ & $14,10^{*}$ & $12,80^{*}$ \\
\hline Fração hexano & 15,20 & $13,70^{*}$ & $13,20^{*}$ & $11,60^{*}$ \\
\hline Fração acetato de etila & 15,20 & $13,30^{*}$ & $13,70^{*}$ & $12,80^{*}$ \\
\hline \multirow[t]{2}{*}{ Fração etanol água } & 15,20 & $15,00^{\mathrm{ns}}$ & $14,10^{\mathrm{ns}}$ & $14,20^{\mathrm{ns}}$ \\
\hline & \multicolumn{4}{|c|}{$\mathrm{G} \%$} \\
\hline Extrato etanólico bruto & 90,50 & $88,50^{\text {ns }}$ & $92,50^{\mathrm{ns}}$ & $76,50^{\text {ns }}$ \\
\hline Fração hexano & 90,50 & $93,50^{\mathrm{ns}}$ & $92,50^{\mathrm{ns}}$ & $90,00^{\mathrm{ns}}$ \\
\hline Fração acetato de etila & 90,50 & $89,50^{\mathrm{ns}}$ & $94,00^{\mathrm{ns}}$ & $93,00^{\mathrm{ns}}$ \\
\hline Fração etanol água & 90,50 & $94,50^{\text {ns }}$ & $91,00^{\text {ns }}$ & $88,00^{\text {ns }}$ \\
\hline
\end{tabular}

* As médias do tratamento diferem entre si $(\mathrm{p} \leq 0,05)$ em comparação com a média do controle, pelo teste de Dunnett. ${ }^{\text {ns }}$ A média do tratamento não difere significativamente da média do controle ( $p>0,05)$. 
maior concentração em alface. Para cebola, somente a FH de $D$. flexuosa, nas maiores concentrações, interferiu na velocidade de germinação (Tab. 2). A percentagem final de germinação não foi diferente do controle em nenhum caso para essa espécie alvo.Quanto ao trigo, houve redução no IVG em todas as concentrações do EEB, FH, fração acetato de etila (FAE) e FEA (Tab. 2). Embora a germinabilidade seja menos sensível que os outros parâmetros analisados, nota-se que em trigo, ao contrário das outras espécies alvo utilizadas, houve inibição da germinação dos diásporos em $14,2 \%, 17,9 \%$ e $14,8 \%$ para o EEB, FAE e FEA, respectivamente (1000 $\left.\mathrm{mg} \mathrm{L}^{-1}\right)$.

Os resultados obtidos em laboratório indicam que o EEB, FAE e FEA não alteraram o IVG da cebola. Esta espécie teste só foi influenciada pela FH. A FEA só influenciou o IVG dos diásporos de trigo. Sendo assim, partindo do pressuposto de que sementes mais vigorosas germinarão mais rapidamente (Piña-Rodriguez et al. 2004), conclui-se que o EEB, FH e FAE interferem no vigor das sementes de alface e tomate; a FH em cebola e o EEB e todas as FS em trigo, atrasando a germinação dessas espécies.

Além dos testes de germinação, os testes biométricos de crescimento (medição da raiz e hipocótilo/coleóptilo) são importantes na determinação de mudanças nas plântulas causadas pelas substâncias-teste (Piña-Rodriguez et al. 2004). Analisando-se os dados da Fig. 1 (A e C) constata-se que a FH estimulou o crescimento da raiz de alface e tomate em todas as concentrações ensaiadas. Para as plântulas de alface submetidas às maiores concentrações do EEB e da FAE também foi observado o mesmo comportamento (Fig. $1 \mathrm{~A}$ ). As raízes de alface quando estimuladas pela $\mathrm{FH}$ mostravam-se mais delgadas e compridas, diferentemente das raízes do controle. O crescimento do hipocótilo de tomate foi reduzido em todas as concentrações da FH e FAE (Fig. 1 D). Nenhum efeito estimulatório ou inibitório foi observado sobre o crescimento do hipocótilo de alface (Fig. 1 B).

$\mathrm{O}$ crescimento da raiz adventícia de cebola não foi inibido nem estimulado em nenhuma situação ensaiada. Quanto ao coleóptilo, as maiores concentrações da FH e a maior concentração do EEB inibiram seu crescimento (Fig. 2 A e B). Observou-se inibição do crescimento inicial da raiz adventícia de trigo (Fig. $2 \mathrm{C}$ ) quando submetidas à $\mathrm{FH}$ e FEA em todas as concentrações ensaiadas e para a maior concentração da FAE. O coleóptilo desta espécie também apresentou inibição quando submetido à $\mathrm{FH}$ e a FEA (Fig. 2 D).

Tabela 2. Índice de velocidade de germinação (IVG) e germinabilidade (\%G) de cebola e trigo submetidas a diferentes concentrações do extrato e frações de $D i$ cranopteris flexuosa, em laboratório.

\begin{tabular}{|c|c|c|c|c|}
\hline \multirow[t]{2}{*}{ Cebola } & \multicolumn{4}{|c|}{ IVG } \\
\hline & Controle & $250 \mathrm{mg} \cdot \mathrm{L}^{-1}$ & $500 \mathrm{mg} \cdot \mathrm{L}^{-1}$ & $1000 \mathrm{mg} \cdot \mathrm{L}^{-1}$ \\
\hline Extrato etanólico bruto & 7,90 & $7,80^{\mathrm{ns}}$ & $7,40^{\mathrm{ns}}$ & $7,00^{\mathrm{ns}}$ \\
\hline Fração hexano & 7,90 & $7,50^{\mathrm{ns}}$ & $6,20^{*}$ & $6,10^{*}$ \\
\hline Fração acetato de etila & 7,90 & $7,50^{\mathrm{ns}}$ & $7,30^{\mathrm{ns}}$ & $6,90^{\mathrm{ns}}$ \\
\hline \multirow[t]{2}{*}{ Fração etanol água } & 7,90 & $7,80^{\mathrm{ns}}$ & $7,50^{\mathrm{ns}}$ & $7,10^{\mathrm{ns}}$ \\
\hline & \multicolumn{4}{|c|}{ G\% } \\
\hline Extrato etanólico bruto & 88,00 & $83,50^{\text {ns }}$ & $80,00^{\text {ns }}$ & $76,50^{\text {ns }}$ \\
\hline Fração hexano & 88,00 & $90,00^{\text {ns }}$ & $77,00^{\text {ns }}$ & $76,50^{\text {ns }}$ \\
\hline Fração acetato de etila & 88,00 & $84,00^{\text {ns }}$ & $83,00^{\text {ns }}$ & $78,50^{\text {ns }}$ \\
\hline Fração etanol água & 88,00 & $89,00^{\text {ns }}$ & $80,50^{\mathrm{ns}}$ & $77,50^{\text {ns }}$ \\
\hline \multirow[t]{2}{*}{ Trigo } & \multicolumn{4}{|c|}{ IVG } \\
\hline & Controle & $250 \mathrm{mg} \cdot \mathrm{L}^{-1}$ & $500 \mathrm{mg} \cdot \mathrm{L}^{-1}$ & $1000 \mathrm{mg} \cdot \mathrm{L}^{-1}$ \\
\hline Extrato etanólico bruto & 13,90 & $11,60^{*}$ & $11,40^{*}$ & $10,40^{*}$ \\
\hline Fração hexano & 13,90 & $11,60^{*}$ & $10,80^{*}$ & $10,90^{*}$ \\
\hline Fração acetato de etila & 13,90 & $11,80^{*}$ & $11,40^{*}$ & $10,10^{*}$ \\
\hline \multirow[t]{2}{*}{ Fração etanol água } & 13,90 & $12,10^{*}$ & $12,10^{*}$ & $11,10^{*}$ \\
\hline & \multicolumn{4}{|c|}{$\mathrm{G} \%$} \\
\hline Extrato etanólico bruto & 81,00 & $71,00^{*}$ & $70,50^{*}$ & $69,50^{*}$ \\
\hline Fração hexano & 81,00 & $74,50^{\text {ns }}$ & $73,50^{\text {ns }}$ & $75,00^{\text {ns }}$ \\
\hline Fração acetato de etila & 81,00 & $74,50^{\text {ns }}$ & $76,50^{\mathrm{ns}}$ & $66,50^{*}$ \\
\hline Fração etanol água & 81,00 & $80,00^{\text {ns }}$ & $76,00^{\mathrm{ns}}$ & $69,00^{*}$ \\
\hline
\end{tabular}

* As médias do tratamento diferem entre si $(\mathrm{p} \leq 0,05)$ em comparação com a média do controle, pelo teste de Dunnett. ${ }^{\text {ns }}$ A média do tratamento não difere significativamente da média do controle $(\mathrm{p}>0,05)$. 

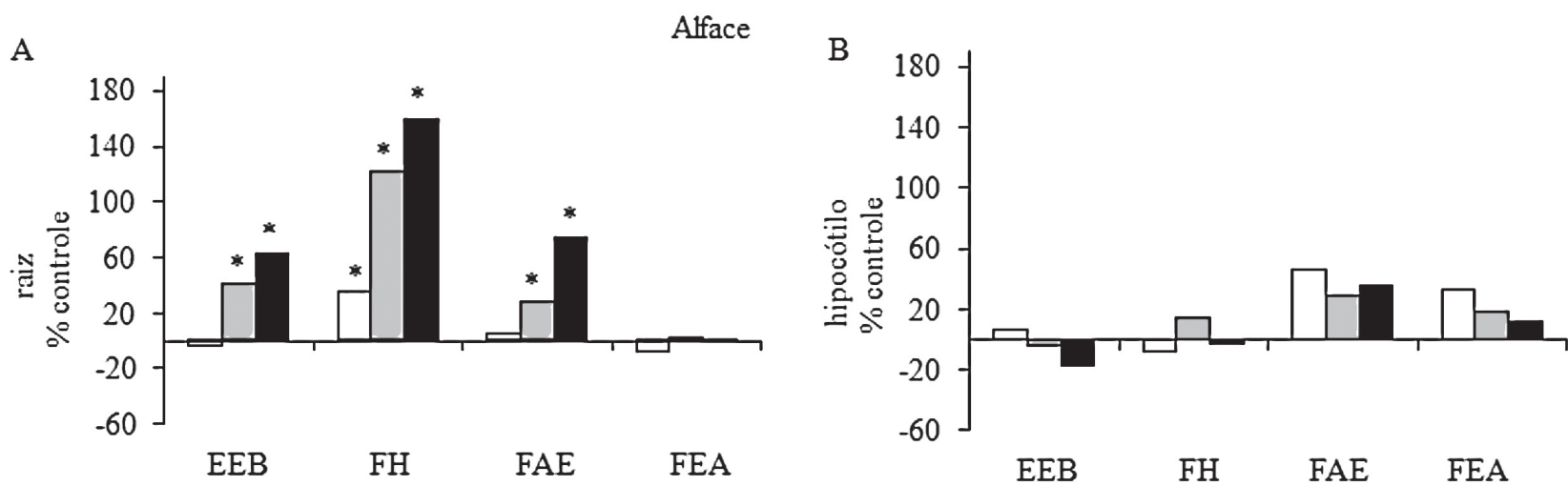

Tomate
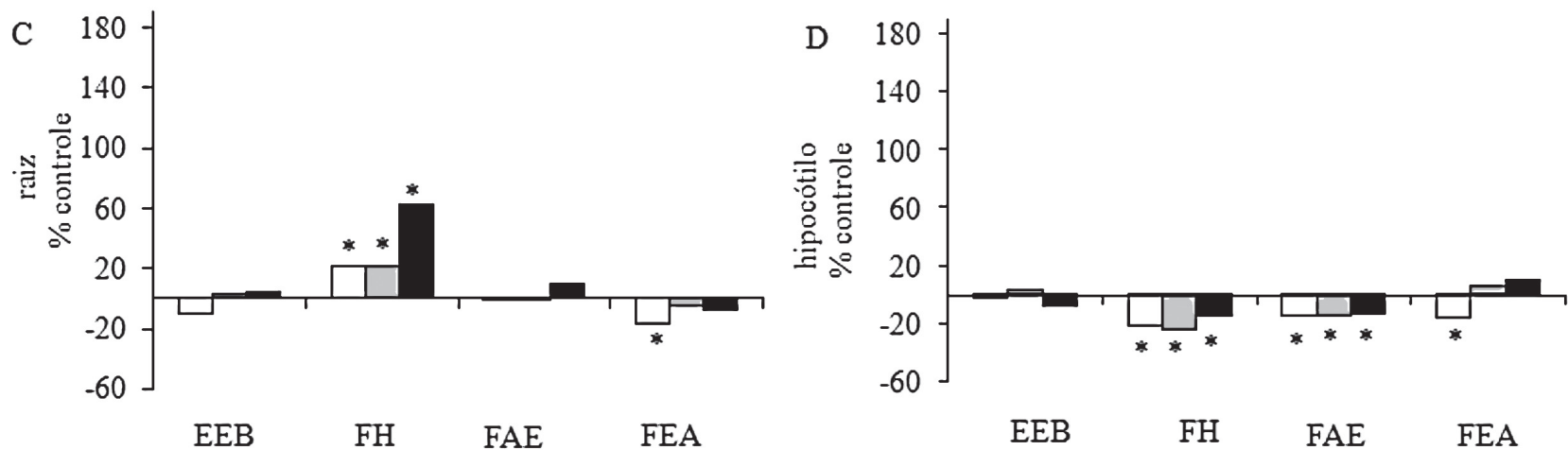

$\square 250 \mathrm{mg} . \mathrm{L}-1 \quad \square 500 \mathrm{mg} . \mathrm{L}-1 \quad \square 1000 \mathrm{mg} . \mathrm{L}-1$

Figura 1. Crescimento da raiz e do hipocótilo de alface (A e B) e tomate (C e D) em diferentes concentrações do extrato etanólico bruto (EEB), fração hexânica (FH), fração acetato de etila (FAE) e fração etanol água (FEA) de Dicranopteris flexuosa, em laboratório. O crescimento é apresentado como porcentagem em relação ao controle. * As médias do tratamento diferem entre si $(\mathrm{p} \leq 0,05)$ em comparação com a média do controle, pelo teste de Dunnett.

Diferenças na alocação de biomassa na parte aérea/raiz podem ser encontradas quando a espécie alvo é submetida a situações estressantes, como a presença de aleloquímicos. Possíveis efeitos causados por diversos aleloquímicos sobre a germinação e crescimento já foram sugeridos. Dentre eles podem-se citar alterações de membranas, na síntese protéica, na respiração, na conformação de moléculas, no alongamento celular e na ultra-estrutura de ápices radiculares (Ferreira 2004).

Dados semelhantes foram apresentados por Jacobi \& Fleck (2000), que relataram inibição do crescimento das raízes de trigo submetidas à escopoletina, uma cumarina exsudada de raízes de Avena spp (aveia). Também foi verificado por Peres et al. (2004) que extratos brutos e frações semipurificadas de Adiantopsis radiata (L.) Fée, Adiantum serratodentatum Humb. \& Bonpl. ex Willd. e Pteris denticulata Sw. (Pteridaceae) inibem tanto o crescimento da raiz quanto do coleóptilo das plântulas de cebola. Cândido et al. 2010 verificaram que o extrato bruto e as frações semipurificadas de Senna occidentalis (L.) Link inibiram o crescimento de alface, tomate, cebola e trigo.

Em casa de vegetação o EEB de D. flexuosa não influenciou a emergências das plântulas alvos (Tab. 3). No crescimento, verifica-se que o EEB estimulou o crescimento da raiz de tomate em todas as concentrações ensaiadas (aproximadamente $69 \%$ ). Já nas monocotiledôneas verifica-se que o EEB inibiu o crescimento da raiz de cebola $(30 \% ; 1000 \mathrm{mg}$ $\mathrm{L}^{-1}$ ) e trigo (37\%) (Fig. 3). Geralmente, as raízes são mais sensíveis aos aleloquímicos do que a parte aérea, mesmo em concentrações muito baixas, pois são mais expostas às substâncias ensaiadas presentes no substrato (Miró et al. 1998). A matéria seca indicou um incremento na parte aérea de alface de 104\% aproximadamente, na concentração de $250 \mathrm{mg} \mathrm{L}^{-1}$ (Tab. 3). A alocação de biomassa entre os vários órgãos do vegetal pode ocorrer em resposta a condições ambientais (Ninkovic 2003). Assim como nesse trabalho, Santos et al. (2002) observaram que houve aumento na biomassa seca do caruru de mancha (Amaranthus viridis L.) quando em contato com o extrato de casca de café (Coffea arabica L.). Em trigo (Tab. 3) também foi observada a redução do número de folhas na concentração de $1000 \mathrm{mg} \mathrm{L}^{-1}$, mas matéria seca da parte aérea foi estimulada na menor concentração ensaiada. Resultados semelhantes foram obtidos com frutos de ervamate (Ilex paraguariensis St. Hill.) incorporados ao solo, que também não afetaram a emergência de milho (Miró et 

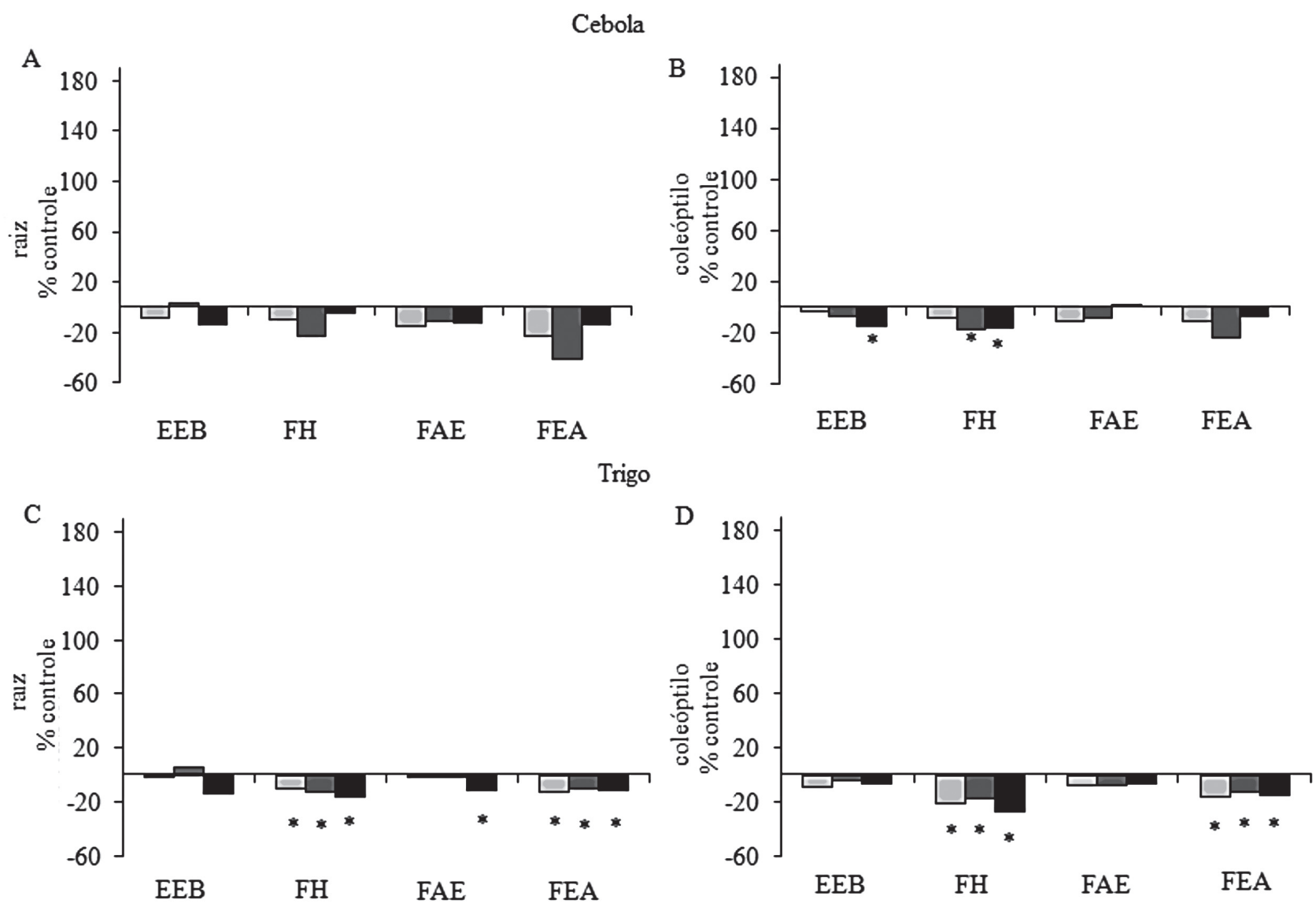

$\square 250 \mathrm{mg} . \mathrm{L}-1 \quad \square 500 \mathrm{mg} . \mathrm{L}-1 \quad \square 1000 \mathrm{mg} . \mathrm{L}-1$

Figura 2. Crescimento da raiz e do coleóptilo de cebola (A e B) e trigo (C e D) em diferentes concentrações do extrato etanólico bruto (EEB), fração hexânica (FH), fração acetato de etila (FAE) e fração etanol água (FEA) de Dicranopteris flexuosa, em laboratório. O crescimento é apresentado como porcentagem em relação ao controle. ${ }^{*}$ As médias do tratamento diferem entre si $(\mathrm{p} \leq 0,05)$ em comparação com a média do controle, pelo teste de Dunnett.

al. 1998). Ao contrário, Pteridium aquilinum (L.) Kuhn em experimentos em casa de vegetação reduziu a emergência de Rubus parviflorus Nutt., R. spectabilis Pursh e Pseudotsuga menziesii (Mirb) Franco, mas não o crescimento do vegetal (Stewart 1975).

Os efeitos fitotóxicos sob condições de casa de vegetação são, geralmente, muito menores do que o impacto gerado em ensaios conduzidos em laboratório. As diferenças observadas entre situações de laboratório e casa de vegetação ocorrem porque, a substância liberada pode, a exemplo dos herbicidas, estar sujeita a processos de retenção e transporte. Apesar disso, semelhanças entre os resultados obtidos em laboratório e em casa de vegetação foram observadas. $\mathrm{O}$ crescimento da raiz de trigo tanto em laboratório quanto em casa de vegetação sofreu interferência do EEB, havendo inibição do crescimento na maior concentração ensaiada.

Resultados de cromatografia em camada delgada (CCD) do EEB e das FS de D. flexuosa sugerem a presença de terpenos no EEB e na FH, presença de compostos fenólicos tanto no EEB quanto na FAE e ausência de alcalóides tanto no EEB quanto nas FS. A presença de terpenos no EEB e na FH corrobora com Aoki et al. (1997) e Munesada et al. (1992) que isolaram terpenos de Gleichenia pectinata, Dicranopteris linearis e D. pedata (Gleicheniaceae), os quais apresentaram potencial alelopático para alface.

Nos testes realizados para a determinação de fenóis totais chegou-se a valores de $78 \mu \mathrm{g}$ de equivalentes de ácido gálico por miligrama de EEB. Dentre as FS, a que apresentou maior valor foi a FAE ( $180 \mu \mathrm{g}$ de equivalente ácido gálico. $\left.\mathrm{mg}^{-1}\right)$, seguida da $\mathrm{FH}(41 \mu \mathrm{g}$ de equivalentes ácido gálico. $\left.\mathrm{mg}^{-1}\right)$ e FEA $\left(34 \mu \mathrm{g}\right.$ de equivalentes ácido gálico.mg $\left.{ }^{-1}\right)$. Para a determinação do conteúdo de flavonóides, o EEB apresentou $37 \mu \mathrm{g}$ de equivalentes de quercetina.mg ${ }^{-1}$. As FH, FAE e FEA apresentaram, respectivamente, valores de 38, 38 e $17 \mu \mathrm{g}$ de equivalentes de quercetina. $\mathrm{mg}^{-1}$.

Compostos fenólicos como ácido ferúlico, p-cumárico, p-hidroxibenzóico e vanílico são produtos do metabolismo secundário isolados de Pteridium aquilinum com atividade alelopática já reportada na literatura (Cooper-Driver 1980). Em milho, compostos fenólicos são produzidos nas folhas, 
Valerí Schmidt da Silva, Ana Carina da Silva Cândido, Caroline Muller, Valdemir Antônio Laura,

Odival Faccenda, Euclésio Simionatto, Sonia Corina Hess e Marize Terezinha Lopes Pereira Peres

Tabela 3. Índice de velocidade de emergência (IVE), porcentagem de emergência e crescimento de alface, tomate, cebola e trigo submetidas a diferentes concentrações do extrato bruto de Dicranopteris flexuosa, em casa de vegetação.

\begin{tabular}{|c|c|c|c|c|}
\hline Alface & Controle & $250 \mathrm{mg} \cdot \mathrm{L}^{-1}$ & $500 \mathrm{mg} \cdot \mathrm{L}^{-1}$ & $1000 \mathrm{mg} . \mathrm{L}^{-1}$ \\
\hline Emergência \% & 55,00 & $55,00^{\text {ns }}$ & $40,00^{\mathrm{ns}}$ & $45,00^{\text {ns }}$ \\
\hline IVE & 0,37 & $0,34^{\mathrm{ns}}$ & $0,23^{\text {ns }}$ & $0,23^{\text {ns }}$ \\
\hline Altura da planta $(\mathrm{cm})$ & 1,79 & $2,03^{\text {ns }}$ & $1,80^{\mathrm{ns}}$ & $1,43^{\text {ns }}$ \\
\hline Número de folhas & 3,68 & $4,13^{\text {ns }}$ & $3,86^{\mathrm{ns}}$ & $3,93^{\text {ns }}$ \\
\hline Massa seca/parte aérea (g) & 0,0044 & $0,0090^{*}$ & $0,0040^{\text {ns }}$ & $0,0043^{\text {ns }}$ \\
\hline Massa seca/ raiz (g) & 0,0026 & $0,0038^{\text {ns }}$ & $0,0043^{\text {ns }}$ & $0,0018^{\text {ns }}$ \\
\hline \multicolumn{5}{|l|}{ Tomate } \\
\hline Emergência \% & 67,50 & $67,50^{\text {ns }}$ & $60,00^{\text {ns }}$ & $45,00^{\text {ns }}$ \\
\hline IVE & 0,28 & $0,31^{\text {ns }}$ & $0,27^{\mathrm{ns}}$ & $0,21^{\text {ns }}$ \\
\hline Altura da planta $(\mathrm{cm})$ & 6,41 & $8,15^{\text {ns }}$ & $7,49^{\text {ns }}$ & $6,36^{\text {ns }}$ \\
\hline Número de folhas & 3,76 & $4,35^{\mathrm{ns}}$ & $4,33^{\mathrm{ns}}$ & $4,67^{\mathrm{ns}}$ \\
\hline Massa seca/parte aérea (g) & 0,0170 & $0,0262^{\text {ns }}$ & $0,0243^{\text {ns }}$ & $0,0242^{\mathrm{ns}}$ \\
\hline Massa seca /raiz (g) & 0,0094 & $0,0166^{\mathrm{ns}}$ & $0,0182^{\text {ns }}$ & $0,0156^{\mathrm{ns}}$ \\
\hline \multicolumn{5}{|l|}{ Cebola } \\
\hline Emergência \% & 55,00 & $52,50^{\text {ns }}$ & $57,50^{\text {ns }}$ & $60,00^{\text {ns }}$ \\
\hline IVE & 0,27 & $0,22^{\mathrm{ns}}$ & $0,26^{\mathrm{ns}}$ & $0,27^{\text {ns }}$ \\
\hline Altura da planta $(\mathrm{cm})$ & 9,67 & $9,68^{\mathrm{ns}}$ & $10,09^{\text {ns }}$ & $9,70^{\mathrm{ns}}$ \\
\hline Número de folhas & 1,62 & $1,74^{\text {ns }}$ & $1,76^{\mathrm{ns}}$ & $1,85^{\text {ns }}$ \\
\hline Massa seca parte aérea $(\mathrm{g})$ & 0,0010 & $0,0018^{\mathrm{ns}}$ & $0,0019^{\text {ns }}$ & $0,0038^{\mathrm{ns}}$ \\
\hline Massa seca da raiz (g) & 0,0002 & $0,0002^{\text {ns }}$ & $0,0003^{\text {ns }}$ & $0,0001^{\text {ns }}$ \\
\hline \multicolumn{5}{|l|}{ Trigo } \\
\hline Emergência \% & 65,00 & $62,50^{\text {ns }}$ & $62,50^{\text {ns }}$ & $67,50^{\text {ns }}$ \\
\hline IVE & 0,46 & $0,62^{\mathrm{ns}}$ & $0,54^{\mathrm{ns}}$ & $0,54^{\mathrm{ns}}$ \\
\hline Altura da planta $(\mathrm{cm})$ & 3,55 & $3,79^{\text {ns }}$ & $4,04^{\text {ns }}$ & $3,68^{\text {ns }}$ \\
\hline Número de folhas & 3,42 & $3,35^{\text {ns }}$ & $3,03^{\text {ns }}$ & $3,01^{*}$ \\
\hline Massa seca parte aérea (g) & 0,0274 & $0,0364^{*}$ & $0,0335^{\text {ns }}$ & $0,0288^{\text {ns }}$ \\
\hline Massa seca/ raiz (g) & 0,0200 & $0,0311^{\mathrm{ns}}$ & $0,0231^{\text {ns }}$ & $0,0230^{\mathrm{ns}}$ \\
\hline
\end{tabular}

* As médias do tratamento diferem entre si $(\mathrm{p} \leq 0,05)$ em comparação com a média do controle, pelo teste de Dunnett. ${ }^{\text {ns }}$ A média do tratamento não difere significativamente da média do controle $(\mathrm{p}>0,05)$.

raízes e pólen e apresentam efeitos negativos em outros vegetais (Santos et al. 2003). Entre as substâncias fenólicas descritas por suas ações alelopáticas podem-se citar também os derivados dos ácidos cinâmico e benzóico, sendo os mais freqüentes clorogênico, $p$-cumárico, cafeíco, siríngico. Representantes pertencentes a classes como cumarinas, quinonas, flavonóides e taninos também são conhecidos como inibidores da germinação de sementes e do crescimento de plantas (Einhellig, 2002).

A distribuição de flavonóides dentro das plantas vasculares sem sementes segue um padrão similar às angiospermas. Os filos basais Psilotophyta e Lycophyta são caracterizados pela presença de flavonas e biflavonas e a total ausência de proantocianidinas e flavonóis. Segundo Swain (1979) citado por Cooper-Driver (1980) um notável avanço na evolução dos flavonóides, em Sphenophyta e
Pteridophyta foi a oxidação da posição 3 levando à síntese de flavonóis e proantocianidinas. Isso foi de fundamental importância no desenvolvimento e sucesso de plantas vasculares "primitivas", desde que ambas as classes de compostos são relatadas com capacidade protetora contra herbívoros e patógenos (Cooper-Driver 1980). Segundo Gottlieb (1987), os taninos condensados estão presentes em $92 \%$ dos gêneros de samambaias examinados, além de metilenobisfloroglucinóis, indanonas sesquiterpenodais e ecdisonas triterpenodais, que são substâncias do metabolismo secundário utilizadas para proteção contra predadadores e patógenos.

O potencial fitotóxico de Dicranopteris flexuosa foi verificado no presente trabalho pela redução da velocidade e/ ou inibição da germinação das sementes alvo ensaiadas em laboratório; EEB e FS provocaram retardo na germinação 


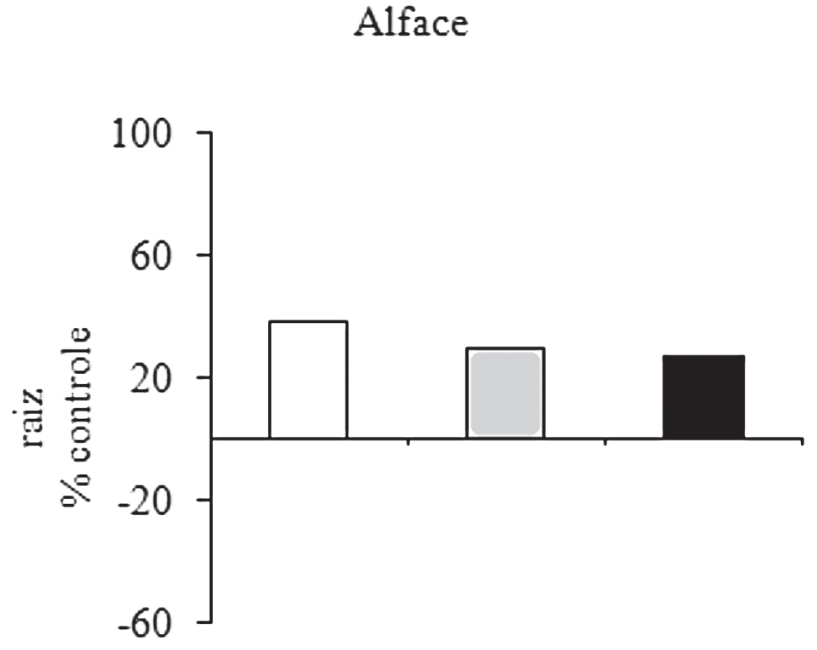

Cebola

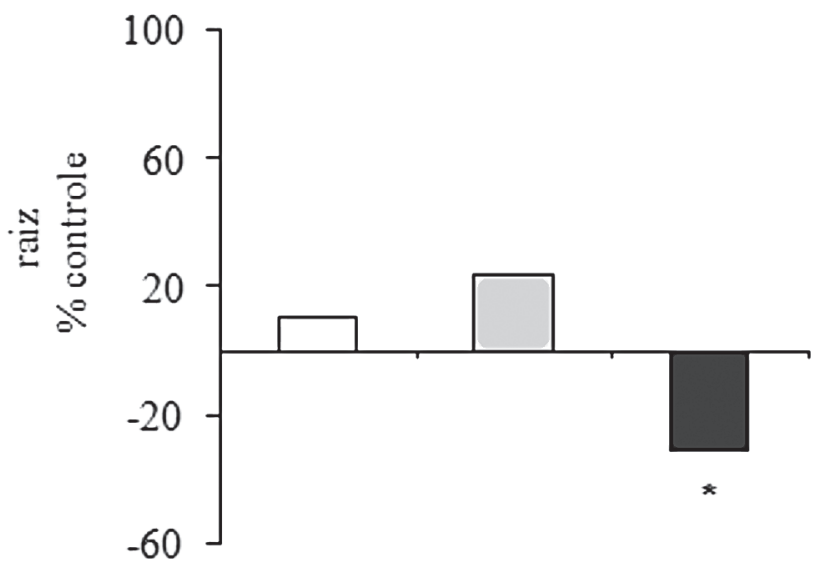

EEB

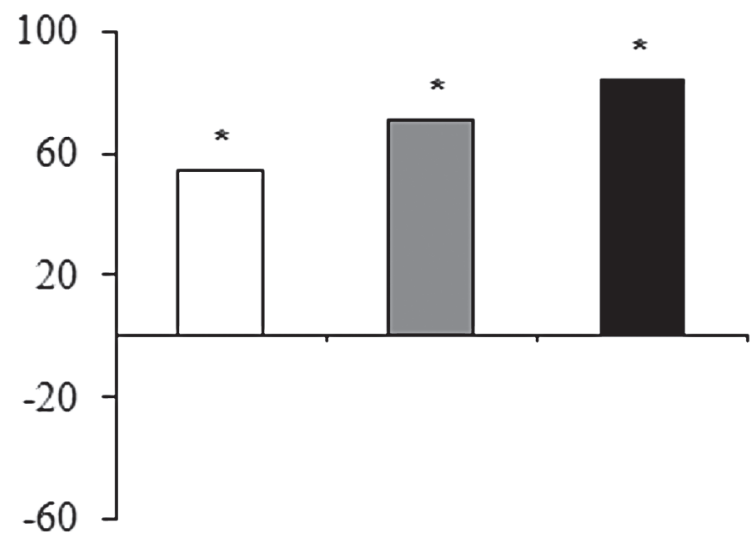

Trigo

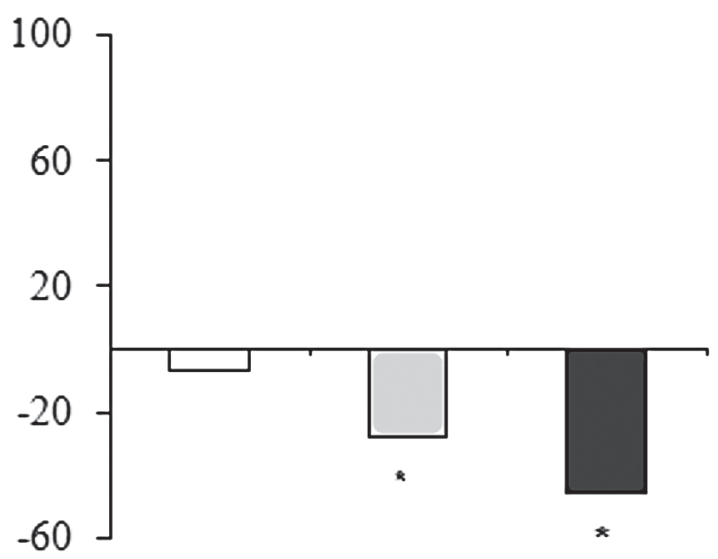

EEB

\section{$\square 250 \mathrm{mg} . \mathrm{L}-1 \quad \square 500 \mathrm{mg} . \mathrm{L}-1 \quad \square 1000 \mathrm{mg} . \mathrm{L}-1$}

Figura 3. Crescimento da raiz de alface, tomate, cebola e trigo em diferentes concentrações do extrato etanólico bruto (EEB) de Dicranopteris flexuosa, em casa de vegetação. $\mathrm{O}$ crescimento é apresentado como porcentagem em relação ao controle. * As médias do tratamento diferem entre si ( $\mathrm{p} \leq 0,05)$ em comparação com a média do controle, pelo teste de Dunnett.

das plantas teste, com exceção da cebola. Também foram observadas modificações no crescimento, onde a maior concentração da $\mathrm{FH}$ provocou crescimento exagerado das raízes de alface. Estímulo esse que também foi observado em tomate, embora em menor intensidade. Além disso, foi observado estímulo e/ou inibição do crescimento radicular e inibição do crescimento do hipocótilo/coleóptilo, bem como alteração da biomassa da parte aérea de alface e trigo em casa de vegetação. Com base nos resultados descritos, é provável que o EEB e FS contenham substâncias que modificam o padrão de germinação e crescimento de alface, tomate, cebola e trigo. Porém são necessários estudos pos- teriores para isolamento e identificação do (s) composto (s) químico (s) com atividade fitotóxica presente nos extratos e frações. Assim essas informações poderão ser úteis para futuras pesquisas para o desenvolvimento de novos e bioativos compostos químicos de produtos naturais.

\section{Agradecimentos}

Agradecemos à profa Ms. Leila Paes Clemente pela identificação botânica. A PROPP/UFMS, FUNDECT/ MS, CNPq e Capes pelo auxílio financeiro e bolsas concedidas. 


\section{Referências bibliográficas}

Aoki, T.; Ohro, T.; Hiraga, Y.; Suga, T.; Uno, M. \& Ohta, S. 1997. Biologically active clerodane-type diterpene glycosides from the root-stalks of Dicranopteris pedata. Phytochemistry 46: 839-844.

Barbosa, L.C.A.; Maltha, C.R.A. \& Borges, E.E.L. 2002. Síntese e avaliação da atividade fitotóxica de lactonas derivadas de 2,4-dimetil-8 oxabiciclo [3.2.1]- oct-6-em-3-ona. Química Nova 25: 203-208.

Brasil. 1992. Ministério da Agricultura e Reforma Agrária. Regras para análise de sementes. Brasília, SNDA/DNDU/CLU.

Cândido, A.C.S.; Schmidt, V.; Laura, V.A.; Faccenda, O.; Hess, S.C.; Simionatto, E. \& Peres, M.T.L.P. 2010. Potencial alelopático da parte aérea de Senna occidentalis (L.) Link (Fabaceae, Caesalpinioideae): Bioensaios em laboratório. Acta Botanica Brasilica 24: 235-242.

Cooper-Driver, G. 1980. The role of flavonoids and related compounds in fern systematics. Bulletin of the Torrey Botanical Club 107: 116-127.

Dayan, F.E.; Romagni, J.G. \& Duke, S.O. 2000. Investigating the mode of action of natural phytotoxins. Journal of Chemical Ecology 26: 2079-2093.

Einhellig, F.A. 2002. The physiology of allelochemical action: clues and views. Pp. 1-23. In: Reigosa, M.J. \& Pedrol, N. (Eds). Allelopathy: From molecules to ecosystems. Science Publishers Inc., Plymouth.

Ferreira, A.G. \& Aquila, M.E.A. 2000. Alelopatia, uma área emergente da ecofisiologia. Revista Brasileira de Fisiologia Vegetal 12 (edição especial): 175-204.

Ferreira, A.G. 2004. Interferência: competição e alelopatia. Pp. 251-262. In: Ferreira, A.G. \& Borghetti, F. (Eds). Germinação: do básico ao aplicado. Porto Alegre, Ed. Artmed.

Gliessman, S.R. \& Muller, C.H. 1972. The phytotoxic potential of bracken (Pteridum aquilinum L.). Madroño 21: 299-304.

Gliessman, S.R. \& Müller, C.H. 1978. The allelopathic mechanisms of dominance in bracken Pteridium aquilinum Southern California. Journal of Chemical Ecology 4: 337-362.

Gottlieb, O.R. 1987. Evolução química vegetal. Ciência e Cultura 39: 357-360.

Hoagland, D.R. \& Arnon, D.I. 1950. The water-culture method for growing plants without soil. Berkeley, California Agricultural Experiment Station.

Jacobi, U.S. \& Fleck, N.G. 2000. Avaliação do potencial alelopático de genótipos de aveia no início do ciclo. Pesquisa Agropecuária Brasileira 35: 11-19.

Labouriau, L.G. 1983. A germinação das sementes. Washington, Secretaria Geral da O.E.A.

Lin, J.Y. \& Tang, C.Y. 2007. Determination of total phenolic and flavonoid contents in selected fruits and vegetables, as well as their stimulatory effects on mouse splenocyte proliferation. Food Chemistry 101: 140-147.

Macias, F.A.; Gallindo, J.C.G. \& Molinillo, J.M.G. 2000. Plant biocommunicators: application of allelopathic studies. Pp. 137-161. In: J.C.
Luijendijk (Ed). 2000 years of natural products research - past, present and future. Leiden, Phytoconsult.

Macias, F.A.; Varela, R.M.; Torres, A.; Oliva, R.M. \& Molinillo, J.M.G. 1998 Bioactive norsesquiterpenes from Helianthus annuus with potential allelopathic activity. Phytochemistry 48: 631-636.

Marcos Filho, J. 2005. Fisiologia de sementes de plantas cultivadas. Piracicaba, Fealq.

Miró, C.P.; Ferreira, A.G. \& Aquila, M.E.A. 1998. Alelopatia de frutos de erva-mate no desenvolvimento do milho. Pesquisa Agropecuária Brasileira 33: 1261-1270.

Munesada, K.; Siddiqui, H.L. \& Suga, T. 1992. Biologically active labdanetype diterpene glycosides from the root-stalks of Gleichenia japonica. Phytochemistry 31: 1533-1536.

Ninkovic, V. 2003. Volatile communication between barley plants affects biomass allocation. Journal of Experimental Botany 54: 1931-1939.

Peres, M.T.L.P.; Silva, L.B.; Faccenda, O. \& Hess, S. 2004. Allelopathic potential of species of Pteridaceae (Pteridophyta). Acta Botanica Brasilica 18: 723-730.

Peres, M.T.L.P.; Pizzolatti, M.G.; Queiroz, M.H. \& Yunes, R.A. 1998. Potencial de atividade alelopática de Gleichenia pectinata Willd (Pr.). Pesquisa Agropecuária Brasileira 33: 131-137.

Piña-Rodriguez, F.C.M.; Figliolia, M.B. \& Peixoto, M.C. 2004. Testes de Qualidade. Pp. 251-262. In: Ferreira, A.G.; Borghetti, F. (Eds). Germinação: do básico ao aplicado. Porto Alegre, Ed. Artmed.

Prates, H.T.; Paes, J.M.V.; Pires, N.M.; Pereira-Filho, I.A.; Oliveira-Júnior, R.S. \& Faria T.C.L. 2000. Efeito do extrato aquoso de leucena na germinação e no desenvolvimento do milho. Pesquisa Agropecuária Brasileira 35: 909-914.

Ranal, M.A. \& Santana, D.G. 2006. How and why to measure the germination process? Revista Brasileira de Botânica 29: 1-11.

Santos, J.C.F.; Souza, I.F.; Mendes, A.N.G.; Morais, A.R.; Conceição, H.E.O. \& Marinho, J.T.S. 2002. Efeito de extratos de cascas de café e de arroz na emergência e no crescimento do caruru-de-mancha. Pesquisa Agropecuária Brasileira 37: 783-790.

Santos, C.C.; Souza, I.F. \& Alves, L.W.R. 2003. Efeitos de restos culturais de milho sobre crescimento de plantas de cafeeiro. Ciência Agrotecnológica 27: 991-1001.

Soares, G.L.G. \& Vieira, T.R. 2000. Inibição da germinação e do crescimento radicular de alface (cv. "Grand rapids") por extratos aquosos de cinco espécies de Gleicheniaceae. Floresta e Ambiente 7: 180-184.

Stewart, R.E. 1975. Allelopathic potential of western braken. Journal of Chemical Ecology 1: 161-169.

Tet-Vun, C. \& Ismail, B.S. 2006. Field evidence of allelopathic properties of Dicranopteris linearis. Weed Biology and Management 6: 59-67.

Wallace, J.W. \& Markham, K.R. 1978. Flavonoids of the primitives ferns: Stromatopteris, Schizeae, Gleichenia, Hymenophyllum and Cardiomanes. American Journal of Botany 65: 965-969.

Windisch, P.G. 1994. Pteridófitas do Estado de Mato Grosso: Gleicheniaceae. Bradea 6: 304-311 